\title{
Beta-blockers in COPD: time for reappraisal
}

\author{
Brian Lipworth ${ }^{1}$, Jadwiga Wedzicha², Graham Devereux ${ }^{3}$, Jørgen Vestbo $^{4}$ and \\ Mark T. Dransfield ${ }^{5,6}$
}

\begin{abstract}
Affiliations: 'Scottish Centre for Respiratory Research, Ninewells Hospital and Medical School, University of Dundee, Dundee, UK. ${ }^{2}$ Airways Disease Section, National Heart and Lung Institute, Imperial College London, London, UK. ${ }^{3}$ Applied Health Sciences, University of Aberdeen, Aberdeen, UK. ${ }^{4}$ Centre for Respiratory Medicine and Allergy, University Hospital South Manchester NHS Foundation Trust, University of Manchester, Manchester, UK. ${ }^{5}$ Lung Health Center, Division of Pulmonary, Allergy and Critical Care Medicine, University of Alabama at Birmingham, Alabama, AL, USA. ${ }^{\circ}$ Birmingham VA Medical Center, Alabama, AL, USA.
\end{abstract}

Correspondence: Brian Lipworth, Scottish Centre for Respiratory Research, Ninewells Hospital and Medical School, University of Dundee, Dundee, DD1 9SY, UK. E-mail: b.j.lipworthadundee.ac.uk

ABSTRACT The combined effects on the heart of smoking and hypoxaemia may contribute to an increased cardiovascular burden in chronic obstructive pulmonary disease (COPD). The use of betablockers in COPD has been proposed because of their known cardioprotective effects as well as reducing heart rate and improving systolic function. Despite the proven cardiac benefits of beta-blockers postmyocardial infarction and in heart failure they remain underused due to concerns regarding potential bronchoconstriction, even with cardioselective drugs. Initiating treatment with beta-blockers requires dose titration and monitoring over a period of weeks, and beta-blockers may be less well tolerated in older patients with COPD who have other comorbidities. Medium-term prospective placebo-controlled safety studies in COPD are warranted to reassure prescribers regarding the pulmonary and cardiac tolerability of beta-blockers as well as evaluating their potential interaction with concomitant inhaled long-acting bronchodilator therapy. Several retrospective observational studies have shown impressive reductions in mortality and exacerbations conferred by beta-blockers in COPD. However, this requires confirmation from long-term prospective placebo-controlled randomised controlled trials. The real challenge is to establish whether beta-blockers confer benefits on mortality and exacerbations in all patients with COPD, including those with silent cardiovascular disease where the situation is less clear.

@ERSpublications

Beta-blockers are used for heart failure and myocardial infarction but remain underused in COPD despite guidelines http://ow.ly/gbvY301wCUA

Editorial comment in Eur Respir J 2016; 48: 600-603.

Received: Nov 062015 | Accepted after revision: May 232016 | First published online: July 072016

Conflict of interest: Disclosures can be found alongside this article at erj.ersjournals.com

Copyright OERS 2016 


\section{Introduction}

Chronic obstructive pulmonary disease (COPD) is one of the world's leading causes of morbidity and is now the third leading cause of mortality, amounting to 3 million deaths in $2010[1,2]$. Exacerbations in particular account for up to three-quarters of the total costs due to COPD [3], with attributable costs exceeding USD 30 billion [4]. A recent COPD task force statement identified an unmet need in terms of finding drugs to treat common comorbidities specifically mentioning the putative effects of beta-blockers on the cardiovascular burden and its associated impact on mortality [5]. Cardiovascular comorbidity is common in patients with COPD due to smoking in addition to other shared risks including genetic susceptibility, systemic inflammation and ageing [6]. The prevalence of COPD in patients with heart failure ranges from $11 \%$ to $52 \%$ in North American patients and from $9 \%$ to $41 \%$ in European patients [7]. The purpose of this article is to critically reappraise current knowledge regarding beta-blockers in COPD, looking at the current evidence for their therapeutic index and how this relates to management guidelines.

We have not attempted a systematic review or meta-analysis as described elsewhere [8-10], but rather highlight the key areas of clinical relevance for physicians who treat patients with COPD. In this article we have: 1) considered the putative link between COPD and the heart in terms of potential targets for beta-blockers; 2) reviewed retrospective data linking the use of beta-blockers to reduced exacerbations and mortality; 3) examined the unmet need for use of beta-blockers in patients with COPD and both known, and potentially unknown, cardiovascular disease; 4) evaluated which beta-blocker to use based on their pharmacology and impact on pulmonary function; and 5) attempted to draw conclusions about the current clinical use of beta-blockers in COPD.

\section{COPD and the heart}

The main accepted clinical indications for the use of beta-blockers in COPD are for patients post-myocardial infarction and for patients with heart failure. However, the presence of untreated or unrecognised (i.e. silent) cardiovascular disease may contribute to mortality in COPD and may also be an underlying causative factor in exacerbations, which can be difficult to separate from respiratory aetiologies (figure 1 and box 1) [6,7]. It is also possible, if not likely, that the burden of cardiovascular disease may be underrated by pulmonologists when treating COPD patients because symptoms are presumed to be primarily driven by airflow obstruction, especially during exacerbations.

The prevalence of left ventricular systolic dysfunction ranges between $10 \%$ and $46 \%$ in patients with COPD, and although the occurrence of heart failure with preserved left ventricular ejection fraction is less clear, estimates in patients with severe COPD are as high as $90 \%$ [7]. The benefits of beta-blockers in

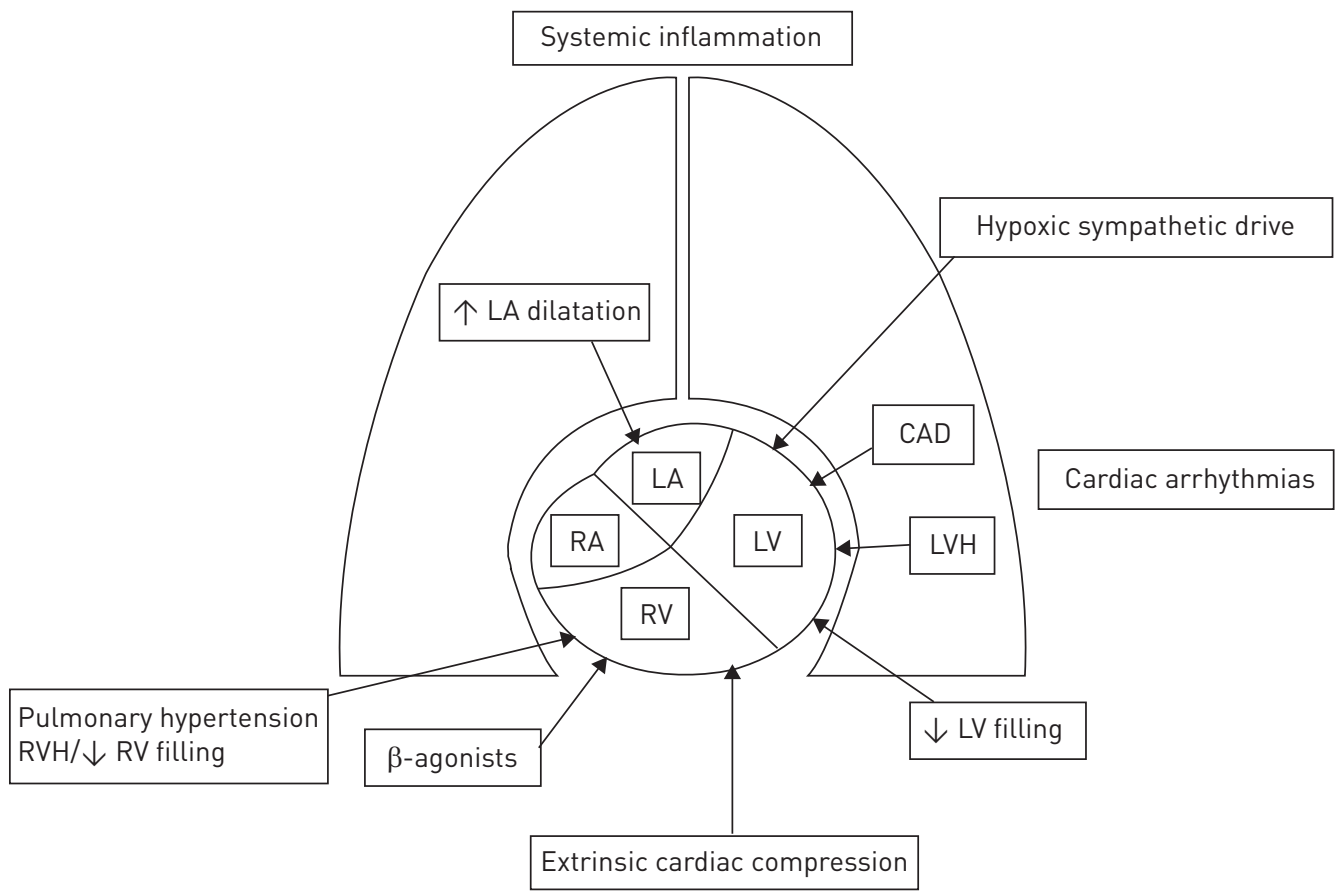

FIGURE 1 Cardiopulmonary interactions in chronic obstructive pulmonary disease. LA: left atrium; LV: left ventricle; RA: right atrium; RV: right ventricle; CAD: coronary artery disease; LVH: left ventricular hypertrophy; RVH: right ventricular hypertrophy. 
BOX 1 Potential cardiac targets for beta-blockers in chronic obstructive pulmonary disease (COPD)

Potential cardiac targets for beta-blockers in COPD

- Improved left ventricular systolic and diastolic function

- Reduced left ventricular dilatation

- Protection against myocardial ischaemia

- Reduced left ventricular mass

- Reduced heart rate

- Anti-arrhythmic effects

- Inhibition of myocyte apoptosis

- Protection against hypoxic sympathetic drive

- Protection against adverse effects of beta-agonists

Potential noncardiac targets for beta-blockers in COPD

- Inhibition of endothelin-1 release

- Reduction in circulating pro-inflammatory cytokines

- Inhibition of neutrophil chemotaxis and respiratory burst

- Reduction in goblet cell number and mucus release

patients with heart failure due to left ventricular systolic dysfunction are well established from pivotal trials as well as meta-analysis [11-14]. The challenge in COPD may be more with respect to diagnosis of heart failure with echocardiography, where image acquisition is difficult due to lung hyperinflation [15].

Beta-blockers only have proven benefits in patients post-myocardial infarction but not in stable coronary arterial disease $[16,17]$. Nevertheless, the presence of coronary calcium on chest computed tomography scans is associated with mortality in COPD [18], and known coronary arterial disease is also associated with longer exacerbations, more dyspnoea, and lower health status and exercise capacity in stable patients with COPD [19]. There is also an acute increase in arterial stiffness, particularly during infective exacerbations of COPD, along with increases in cardiac enzymes especially in patients with coronary arterial disease [20]; one particular study found that one in 12 patients admitted to hospital with an exacerbation of COPD met the criteria for a myocardial infarction [21]. The presence of coronary heart disease in COPD, along with the adverse effects of hypoxaemia [22], may be compounded by the positive chronotropic effects of concomitant inhaled beta-agonist therapy [23, 24], further compromising cardiac reserve. It has been shown that even a low dose of a beta-1 selective antagonist such as atenolol might protect against chronotropic, inotropic and electrocardiographic effects of inhaled beta-agonists, which are mediated by cardiac beta-2 receptor stimulation [25].

Another potential target is diastolic dysfunction, although a meta-analysis suggests that the beneficial effects of beta-blockers in such patients are less clear cut [26]. Several factors may contribute to the occurrence of impaired diastolic function in COPD. First, patients with COPD also appear to have a higher left ventricular mass (hypertrophy) even in the absence of left ventricular dilatation, which impacts upon survival [27]. Secondly, lung hyperinflation in COPD may cause cardiac compression reducing both left ventricular and atrial filling even in the absence of raised pulmonary arterial pressure [28-30]. These factors may also be compounded by the negative effects of hypoxaemia on diastolic filling [22, 31].

In addition to these COPD-related risks, patients with the disease commonly have other comorbidities such as coronary artery disease, hypertension and diabetes, which can all adversely affect diastolic function. This was addressed in a recent prospective longitudinal study of healthy young adults followed over 25 years, where a fall in the ratio of forced expiratory volume in $1 \mathrm{~s}$ (FEV1) to forced vital capacity (FVC) was associated with reduced left atrial size and cardiac output [32]. Left ventricular end diastolic and end systolic wall stress measured by magnetic resonance imaging is associated with increasing severity of airflow obstruction in patients with COPD and coexistent heart failure [33]. Impaired left ventricular filling is clinically important because it can eventually produce left atrial enlargement, which is a key risk factor for atrial fibrillation and associated mortality during exacerbations of COPD [34]. Furthermore, the presence of impaired diastolic filling in patients with COPD is also related to impaired walking distance [35]. Thus, the absence of benefits of beta-blockers in diastolic dysfunction may not apply in COPD and deserves re-evaluation in this patient group.

\section{Effects of beta-blockers on mortality and exacerbations}

Due to the high cardiovascular comorbidity in COPD from smoking along with increased sympathetic drive due to hypoxaemia [36], beta-blockers have been proposed as a cogent therapeutic intervention for 
their known cardioprotective effects in addition to reducing heart rate and improving systolic and diastolic dysfunction. One of the fundamental issues with regards to more widespread use of beta-blockers in COPD is the concern regarding beta-2 receptor antagonism and associated airway smooth muscle constriction, which may even occur with cardioselective agents that exhibit preferential beta-1 blockade, especially in more susceptible severe patients with impaired respiratory reserve. The risk-benefit equation in COPD becomes more favourable for patients who already have overt cardiac disease such as heart failure or post-myocardial infarction, where beta-blockers have proven protective effects [11, 16]. There are, however, no data as to the putative beneficial effects of beta-blockers in those COPD patients who may have concomitant silent coronary arterial disease or heart failure.

Retrospective observational data have shown beneficial effects of beta-blockers in a cohort of 5977 patients with COPD who were followed for a mean of 4.35 years [37], where their use was associated with an overall $22 \%$ (95\% CI 8-33\%) reduction in mortality. In a study of 825 patients admitted to hospital for an exacerbation of COPD, beta-blocker use among 142 patients was associated with a $61 \%$ (95\% CI 1-86\%) reduction in mortality [38]. RUTTEN et al. [39] showed 32\% (95\% CI 17-44\%) and 29\% (95\% CI 17-40\%) reductions in mortality and exacerbations, respectively, conferred by taking beta-blockers among 2230 patients with COPD followed up for a mean of 7.2 years. In a cohort study from Sweden of 4858 patients with COPD, those who were discharged on a beta-blocker (84\%) post-myocardial infarction had 13\% (95\% CI 2-22\%) lower mortality [40]. In a retrospective report of 256 patients with COPD who had either coronary heart disease or heart failure, 58\% were taking beta-blockers associated with a 73\% (95\% CI 50$85 \%)$ reduction in the likelihood of being admitted to a hospital emergency room [41]. In contrast, in an observational study using time dependent analysis of 2249 severe oxygen-dependent COPD patients there was a $19 \%$ increase in mortality associated with taking beta-blockers [42]. However, in a prospectively followed cohort of 3464 patients, BнAтT et al. [43] found a 27\% (95\% CI 10-40\%) reduction in total exacerbations, while in Global Initiative for Chronic Obstructive Lung Disease grade 3/4 patients on home oxygen there was a $67 \%$ reduction ( $95 \%$ CI $42-81 \%)$.

In a 2012 meta-analysis of nine retrospective cohort studies, the pooled estimate for mortality reduction with beta-blockers was reported to be $31 \%$ (95\% CI 22-38\%) [8]. In a subsequent 2014 meta-analysis of 15 retrospective studies of 21596 patients with COPD, the pooled estimate for reduction in overall mortality conferred by beta-blockers was $28 \%$ (95\% CI $17-37 \%$ ) and for exacerbations was 38\% (95\% CI $18-58 \%$ ) [9]. The reduction in mortality was 36\% (95\% CI 24-46\%) among the subgroup of patients (five studies; 39\% weighting) with known coronary heart disease and 26\% (95\% CI 7-42\%) in the subgroup with known heart failure (three studies; 18\% weighting).

The beneficial effects of beta-blockers on exacerbations may involve other potential noncardiac mechanisms whereby beta-blockers could reduce COPD exacerbations [44, 45]. In heart failure, use of cardioselective beta-blockers reduces systemic inflammatory cytokine release such as interleukin-6 and alters leukocyte distribution, which may also impact inflammation during respiratory infections [46]. Beta-blockers have also been reported to inhibit neutrophil chemotaxis and oxygen free radical production [47], while in human endothelial cells they have been reported to reduce the release of endothelin-1, a bronchoconstrictor peptide implicated in the pathogenesis of COPD exacerbations $[48,49]$.

It is not possible to eliminate the possibility of residual confounding in the observational studies suggesting beta-blockers may reduce exacerbations and mortality in COPD and thus definitive randomised trials are needed. There is now a planned placebo-controlled trial powered for a reduction in exacerbations using metoprolol over 1 year via the US COPD Clinical Research Network and funded by the Department of Defense (Clinicaltrials.gov identifier: NCT02587351).

This study will exclude those patients with an absolute indication for beta-blockers including an myocardial infarction or revascularisation procedure within 3 years or with an ejection fraction $<40 \%$. However, it remains possible that this and similar studies may run the risk of only including patients where beta-blockers are less efficacious.

\section{The unmet cardiac need in COPD}

Beta-blockers have an established position in the management of coronary artery disease while heart failure guidelines reinforce their use in patients with concomitant COPD [50]. Similarly, COPD management strategies also state that the benefits of selective beta-1 blocker treatment in heart failure clearly outweigh any potential risk associated with treatment even in patients with severe COPD [51]. Despite this guidance there is a reluctance to prescribe even cardioselective beta-blockers in COPD, even in the presence of known cardiac disease, because of persistent concerns regarding potential bronchoconstriction, especially in more severe patients. In a cohort from Scotland we found that only $14 \%$ of patients with COPD were taking beta-blockers for cardiovascular comorbidity [37]. Further evidence of a reluctance to prescribe beta-blockers 
in COPD was documented by QuinT et al. [52] where 55\% of patients who had a myocardial infarction were not prescribed a beta-blocker, with only $22 \%$ being prescribed on admission. In the UK $64 \%$ of patients without COPD and acute coronary syndrome were prescribed beta-blockers as compared with $16 \%$ of similar patients with COPD who were prescribed beta-blockers [53]. Furthermore COPD was documented as a reason for withholding beta-blockers in $33 \%$ of patients who did not receive a beta-blocker, while noncardiologists were $40 \%$ less likely to prescribe beta-blockers. In the USA, CHEN et al. [54] found that elderly patients after an acute myocardial infarction were $62 \%$ less likely to be given beta-blockers in the presence of a history of treated COPD or asthma. Initiating treatment with beta-blockers is not simple as it requires dose titration over a period of weeks along with monitoring of heart rate, blood pressure and perhaps spirometry, all of which take time, incurring extra healthcare costs. Moreover beta-blockers may be less well tolerated in older patients with coexisting comorbidities such as diabetes, peripheral vascular disease and renal impairment, who are more prone to postural hypotension.

\section{Choice of beta-blocker and effects on pulmonary function}

The mechanism of beta-blocker induced bronchoconstriction is thought to be due to the effects of pre- and post-junctional beta-2 receptor antagonism uncovering the prevailing cholinergic tone via post-junctional smooth muscle muscarinic type 3 receptors, resulting in airway smooth muscle constriction [55].

In a subgroup analysis of 2712 patients from a cohort who had serial spirometry measures over 4 years, there was no deleterious effect of long-term beta-blocker use ( $88 \%$ were cardioselective) on either FEV1 or FVC, even among the more severe patients taking triple inhaled therapy, who had the greatest reductions in exacerbations and mortality [37]. In a meta-analysis of randomised controlled trials with cardioselective beta-blockers there was no significant change in FEV1 compared with placebo, when given either as single $-2.1 \%$ (95\% CI $-6.1-2.0 \%)$ or chronic dosing $-2.6 \%$ (95\% CI $-5.9-0.8 \%)$, and also no significant effect on the FEV1 response to beta-2-agonists [10]. In a randomised controlled trial of 27 patients with heart failure who also had coexistent moderate-to-severe COPD, after 4 months of treatment there was a $190 \mathrm{~mL}$ significant fall in FEV1 between bisoprolol and placebo, while salbutamol reversibility, symptoms and quality of life were unchanged [56]. In a comparison of bisoprolol and placebo in patients with moderate-to-severe COPD, there was a significantly worsening of dynamic hyperinflation during cycle endurance while exercise duration was unaltered [57]. In a study comparing 24 COPD patients on beta-blockers matched to patients not taking beta-blockers there was no difference in exercise capacity or gas exchange despite lower heart rate and blood pressure, in turn suggesting great oxygen delivery per heart beat [58].

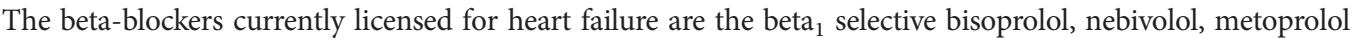
and the non-selective carvedilol (box 2). As has already been shown in heart failure [59] and asthma [60] it is important to slowly titrate up the dose of beta-blocker to improve cardiovascular and pulmonary tolerability. Bisoprolol has a licensed indication for use in heart failure and coronary artery disease and has a beta-1/2 receptor selectivity ratio of $14: 1$, which is higher than either atenolol (5:1) or metoprolol (2:1) [61]. In a cross-over study of 51 patients with COPD and heart failure, directly comparing 6 weeks of bisoprolol, metoprolol and carvedilol [62], FEV1 was lowest with carvedilol and highest with bisoprolol with metoprolol in between. In a randomised controlled trial comparing bisoprolol (mean dose $6.4 \mathrm{mg}$ ) and carvedilol (mean dose $47 \mathrm{mg}$ ) in patients with heart failure and COPD, FEV1 significantly improved by $137 \mathrm{~mL}$ with bisoprolol, but not with carvedilol (30 mL improvement) [63]. In 15 mild-to-moderate COPD patients there

BOX 2 Prescribing of beta-blockers in chronic obstructive pulmonary disease for cardiovascular disease

- Beta-1 selective antagonists including metoprolol, bisoprolol and nebivolol exhibit dose related beta-2 receptor blockade

- Carvedilol is a nonselective beta-antagonist that is more likely to cause bronchoconstriction than beta-1 selective antagonists

- Slowly titrate the dose of beta-blockers at 1-2 weekly intervals up to the usual maintenance dose

- Monitor supine and erect blood pressure, heart rate and spirometry during dose titration

- Concomitant long-acting muscarinic antagonists may obviate potential bronchoconstriction

- Symptomatic bradycardia may occur if beta-blockers are used with other rate-limiting drugs such as calcium blockers (e.g. verapamil and diltiazem), ivabradine or anti-arrhythmic agents (e.g. digoxin, amiodarone and flecainide)

- Symptomatic hypotension may occur when beta-blockers are used with other vasodilatory drugs le.g. angiotensin converting enzyme inhibitors, angiotensin receptor blockers, calcium channel blockers and alpha receptor blockers) 
was a significant worsening in airway hyperreactivity to methacholine challenge with metoprolol and propranolol, but not celiprolol compared with placebo, while the acute bronchodilator response to fenoterol was only blunted by propranolol [64].

Nebivolol has been shown to exhibit greater in vitro beta-1/2 receptor selectivity than bisoprolol in human myocardium [65] and also suppresses endothelial nitric oxide [66]. In healthy volunteers attenuation of beta-2 receptor mediated terbutaline-induced hypokalaemia was significantly greater with bisoprolol $10 \mathrm{mg}$ or atenolol $50 \mathrm{mg} / 100 \mathrm{mg}$ versus nebivolol $5 \mathrm{mg}$, which in turn was not different from placebo [67]. Nebivolol produced significant blunting of terbutaline-induced glucose and insulin responses compared with placebo in keeping with beta-2 receptor antagonism at the $5 \mathrm{mg}$ dose. However, the relative beta-1/2 selectivity cannot be inferred since this would require comparison of beta-blocker doses that exhibit the same degree of beta- 1 antagonism as assessed by exercise heart rate reduction [68], which was not measured.

In a post hoc analysis of 2670 patients from the Organized Program to Initiate Lifesaving Treatment in Hospitalized Patients with Heart Failure (OPTIMIZE-HF), there were no differences between selective and non-selective beta-blockers in terms of lower mortality or re-hospitalisation in patients with and without COPD [69]. Carvedilol blocks cardiac beta-1 and beta-2 receptors as well as exhibiting peripheral vasodilatation due to alpha receptor blockade, which in addition to its antioxidant activity [70] may explain its superiority versus metoprolol in heart failure in one particular study, which may not have compared comparable doses [59]. Until there is more convincing evidence to support the superiority of carvedilol in heart failure, it would be prudent to choose a selective agent such as bisoprolol, nebivolol or metoprolol due to their superior safety profile in COPD.

Long-acting muscarinic antagonists such as tiotropium have been shown to obviate bronchoconstriction even when using nonselective beta-blockade with propranolol in asthmatic patients [71]. It is the more severe COPD patients who would, in theory, be most at risk of beta-blocker induced bronchoconstriction. These patients would usually already be taking concomitant long-acting muscarinic antagonists and hence be protected from bronchospasm. The relatively small degree of dose-related beta-2 receptor antagonism conferred, for example, by bisoprolol [72] would not be expected to result in worsening of pulmonary function. It is also important to consider the potential impact of beta-2 receptor genotype on the risk-benefit equation for beta-blockers in COPD. It has been shown that asthmatic patients who possess one or two copies of the arginine- 16 beta- 2 receptor polymorphism are more prone to propranolol-induced bronchoconstriction in terms of FEV1 and airway resistance [73]. While the arginine-16 polymorphism conferred a worse outcome on survival in patients receiving metoprolol after an acute coronary syndrome [74], it was not associated with survival in heart failure patients treated with metoprolol or carvedilol [75].

\section{Conclusions and the way forward}

There are compelling reasons to use cardioselective beta-blockers in patients with COPD who have coexistent heart failure or are post-myocardial infarction (box 3). Current evidence would suggest that

\section{BOX 3 Key messages}

- Cardiovascular comorbidity, including coronary artery disease and heart failure, commonly coexists in chronic obstructive pulmonary disease (COPD) due to the effects of smoking, systemic inflammation, hypoxaemia and other shared risks.

- COPD may also be associated with impaired diastolic filling due to lung hyperinflation, which may be compounded by the negative lusitropic effects of hypoxaemia and left ventricular hypertrophy.

- The main indications for beta-blockers in patients with COPD are post-myocardial infarction and heart failure with reduced ejection fraction. Despite clear evidence beta-blockers improve outcomes in these COPD patients they remain significantly underused due to concerns about adverse respiratory effects, even with beta-1 selective antagonists.

- Meta-analyses of retrospective studies with beta-blockers in COPD have shown pooled estimates for reductions in mortality of $28 \%$ and exacerbations of $38 \%$.

- Initiating treatment with beta-blockers requires careful dose titration and monitoring. This may be particularly relevant for patients with COPD who are often older and have other comorbidities that increase the risk of intolerance.

- Beta-1 selective antagonists such as bisoprolol, nebivolol and metoprolol are preferred to the nonselective carvedilol as they are less likely to produce bronchoconstriction in COPD.

- Long-acting muscarinic antagonists, which are commonly used in COPD, protect against the potential for bronchoconstriction due to dose related beta-2 receptor antagonism.

- The key unanswered question is whether beta-blockers may confer benefits on mortality and exacerbations in all patients with COPD including those with silent cardiovascular disease. 
there remains a reticence to prescribe beta-blockers in such patients because of a fear of adverse events, particularly worsened lung function. Further prospective medium-term safety studies are therefore required to carefully follow the effects of cardioselective drugs on pulmonary function in patients with more severe COPD by employing slow initial dose titration as well as evaluating their interaction with long-acting bronchodilators (Clinicaltrials.gov identifier: NCT01656005).

There is currently not sufficient evidence at present to advocate treatment with beta-blockers for the prevention of exacerbations or exacerbation-related mortality. Long-term placebo-controlled multicentre trials in COPD are indicated to confirm the benefits of beta-blockers already seen on mortality and exacerbations in observational studies. The key question to answer is whether the potential benefits of beta-blockers are confined to those patients with known cardiovascular disease or are present in the wider population who may have silent cardiovascular disease. Likewise, beta-blockers are not currently indicated in COPD patients with diastolic dysfunction alone where controlled trials are also warranted.

Beta-blockers are likely to be part of a more complex therapeutic jigsaw in addressing the composite risk from different cardiovascular abnormalities in COPD, and as has already been shown with heart failure there may be additive effects from drugs acting on other neuro-hormonal pathways. This includes drugs which block the renin-angiotensin system that may be particularly effective at regressing left ventricular hypertrophy [76]. Dual angiotensin/neprilysin inhibition may also confer benefits by augmenting brain natriuretic peptide levels [77] and ameliorating the adverse effects of hypoxic pulmonary vasoconstriction $[78,79]$. Anti-platelet drugs might also be beneficial for treating silent coronary artery disease in more severe COPD patients who are oxygen dependent [42]. Pulmonologists have tended to focus on drugs which act on the lung rather than the heart, because of the evidence supporting the former. Perhaps now is time to look at the lungs' next door neighbour in the chest and begin to address the unmet need of cardiac disease in COPD.

\section{Acknowledgements}

All authors contributed to the literature search, writing and presentation of the manuscript, and approval of the final version.

\section{References}

1 Lozano R, Naghavi M, Foreman K, et al. Global and regional mortality from 235 causes of death for 20 age groups in 1990 and 2010: a systematic analysis for the Global Burden of Disease Study 2010. Lancet 2012; 380: 2095-2128.

2 Lopez-Campos JL, Ruiz-Ramos M, Soriano JB. Mortality trends in chronic obstructive pulmonary disease in Europe, 1994-2010: a joinpoint regression analysis. Lancet Respir Med 2014; 2: 54-62.

3 Guarascio AJ, Ray SM, Finch CK, et al. The clinical and economic burden of chronic obstructive pulmonary disease in the USA. Clinicoecon Outcomes Res 2013; 5: 235-245.

4 Ford ES, Murphy LB, Khavjou O, et al. Total and state-specific medical and absenteeism costs of COPD among adults aged $\geqslant 18$ years in the United States for 2010 and projections through 2020. Chest 2015; 147: 31-45.

5 Celli BR, Decramer M, Wedzicha JA, et al. An official American Thoracic Society/European Respiratory Society statement: research questions in chronic obstructive pulmonary disease. Am J Respir Crit Care Med 2015; 191: e4-e27.

6 Bhatt SP, Dransfield MT. Chronic obstructive pulmonary disease and cardiovascular disease. Transl Res 2013; 162 : 237-251.

7 Hawkins NM, Petrie MC, Jhund PS, et al. Heart failure and chronic obstructive pulmonary disease: diagnostic pitfalls and epidemiology. Eur J Heart Fail 2009; 11: 130-139.

8 Etminan M, Jafari S, Carleton B, et al. Beta-blocker use and COPD mortality: a systematic review and meta-analysis. BMC Pulm Med 2012; 12: 48.

9 Du Q, Sun Y, Ding N, et al. Beta-blockers reduced the risk of mortality and exacerbation in patients with COPD: a meta-analysis of observational studies. PLoS One 2014; 9: e113048.

10 Salpeter SR, Ormiston TM, Salpeter EE, et al. Cardioselective beta-blockers for chronic obstructive pulmonary disease: a meta-analysis. Respir Med 2003; 97: 1094-1101.

11 Chatterjee S, Biondi-Zoccai G, Abbate A, et al. Benefits of $\beta$ blockers in patients with heart failure and reduced ejection fraction: network meta-analysis. BMJ 2013; 346: f55.

12 The Cardiac Insufficiency Bisoprolol Study II (CIBIS-II): a randomised trial. Lancet 1999; 353: 9-13.

13 Packer M, Fowler MB, Roecker EB, et al. Effect of carvedilol on the morbidity of patients with severe chronic heart failure: results of the carvedilol prospective randomized cumulative survival (COPERNICUS) study. Circulation 2002; 106: 2194-2199.

14 Effect of metoprolol CR/XL in chronic heart failure: Metoprolol CR/XL Randomised Intervention Trial in Congestive Heart Failure (MERIT-HF). Lancet 1999; 353: 2001-2007.

15 Hawkins NM, Petrie MC, Macdonald MR, et al. Heart failure and chronic obstructive pulmonary disease the quandary of Beta-blockers and Beta-agonists. J Am Coll Cardiol 2011; 57: 2127-2138.

16 Freemantle N, Cleland J, Young P, et al. beta Blockade after myocardial infarction: systematic review and meta regression analysis. BMJ 1999; 318: 1730-1737.

17 Bangalore S, Steg G, Deedwania P, et al. $\beta$-Blocker use and clinical outcomes in stable outpatients with and without coronary artery disease. JAMA 2012; 308: 1340-1349.

18 Williams MC, Murchison JT, Edwards LD, et al. Coronary artery calcification is increased in patients with COPD and associated with increased morbidity and mortality. Thorax 2014; 69: 718-723.

19 Patel AR, Donaldson GC, Mackay AJ, et al. The impact of ischemic heart disease on symptoms, health status, and exacerbations in patients with COPD. Chest 2012; 141: 851-857. 
20 Patel AR, Kowlessar BS, Donaldson GC, et al. Cardiovascular risk, myocardial injury, and exacerbations of chronic obstructive pulmonary disease. Am J Respir Crit Care Med 2013; 188: 1091-1099.

21 McAllister DA, Maclay JD, Mills NL, et al. Diagnosis of myocardial infarction following hospitalisation for exacerbation of COPD. Eur Respir J 2012; 39: 1097-1103.

22 Cargill RI, Kiely DG, Lipworth BJ. Adverse effects of hypoxaemia on diastolic filling in humans. Clin Sci (Lond) 1995; 89: 165-169.

23 Kiely DG, Cargill RI, Grove A, et al. Abnormal myocardial repolarisation in response to hypoxaemia and fenoterol. Thorax 1995; 50: 1062-1066.

24 Kiely DG, Cargill RI, Lipworth BJ. Cardiopulmonary interactions of salbutamol and hypoxaemia in healthy young volunteers. Br J Clin Pharmacol 1995; 40: 313-318.

25 Newnham DM, Wheeldon NM, Lipworth BJ, et al. Single dosing comparison of the relative cardiac beta 1/beta 2 activity of inhaled fenoterol and salbutamol in normal subjects. Thorax 1993; 48: 656-658.

26 Bavishi C, Chatterjee S, Ather S, et al. Beta-blockers in heart failure with preserved ejection fraction: a meta-analysis. Heart Fail Rev 2015; 20: 193-201.

27 Short PM, Anderson WJ, Elder DH, et al. Impact of left ventricular hypertrophy on survival in chronic obstructive pulmonary disease. Lung 2015; 193: 487-495.

28 Boussuges A, Pinet C, Molenat F, et al. Left atrial and ventricular filling in chronic obstructive pulmonary disease. An echocardiographic and Doppler study. Am J Respir Crit Care Med 2000; 162: 670-675.

29 Funk GC, Lang I, Schenk P, et al. Left ventricular diastolic dysfunction in patients with COPD in the presence and absence of elevated pulmonary arterial pressure. Chest 2008; 133: 1354-1359.

30 Butler J, Schrijen F, Henriquez A, et al. Cause of the raised wedge pressure on exercise in chronic obstructive pulmonary disease. Am Rev Respir Dis 1988; 138: 350-354.

31 Smith BM, Prince MR, Hoffman EA, et al. Impaired left ventricular filling in COPD and emphysema: is it the heart or the lungs? The Multi-Ethnic Study of Atherosclerosis COPD Study. Chest 2013; 144: 1143-1151.

32 Cuttica MJ, Colangelo LA, Shah SJ, et al. Loss of lung health from young adulthood and cardiac phenotypes in middle age. Am J Respir Crit Care Med 2015; 192: 76-85.

33 Alter P, van de Sand K, Nell C, et al. Airflow limitation in COPD is associated with increased left ventricular wall stress in coincident heart failure. Respir Med 2015; 109: 1131-1137.

34 Steer J, Gibson J, Bourke SC. The DECAF Score: predicting hospital mortality in exacerbations of chronic obstructive pulmonary disease. Thorax 2012; 67: 970-976.

35 Watz H, Waschki B, Meyer T, et al. Decreasing cardiac chamber sizes and associated heart dysfunction in COPD: role of hyperinflation. Chest 2010; 138: 32-38.

36 Heindl S, Lehnert M, Criee CP, et al. Marked sympathetic activation in patients with chronic respiratory failure. Am J Respir Crit Care Med 2001; 164: 597-601.

37 Short PM, Lipworth SI, Elder DH, et al. Effect of beta blockers in treatment of chronic obstructive pulmonary disease: a retrospective cohort study. BMJ 2011; 342: d2549.

38 Dransfield MT, Rowe SM, Johnson JE, et al. Use of beta blockers and the risk of death in hospitalised patients with acute exacerbations of COPD. Thorax 2008; 63: 301-305.

39 Rutten FH, Zuithoff NP, Hak E, et al. Beta-blockers may reduce mortality and risk of exacerbations in patients with chronic obstructive pulmonary disease. Arch Intern Med 2010; 170: 880-887.

40 Andell P, Erlinge D, Smith JG, et al. $\beta$-blocker use and mortality in COPD patients after myocardial infarction: a Swedish nationwide observational study. J Am Heart Assoc 2015; 4: e001611.

41 Puente-Maestu L, Calle M, Ortega-González A, et al. Multicentric study on the beta-blocker use and relation with exacerbations in COPD. Respir Med 2014; 108: 737-744.

42 Ekström MP, Hermansson AB, Ström KE. Effects of cardiovascular drugs on mortality in severe chronic obstructive pulmonary disease. Am J Respir Crit Care Med 2013; 187: 715-720.

43 Bhatt SP, Wells JM, Kinney GL, et al. $\beta$-Blockers are associated with a reduction in COPD exacerbations. Thorax 2016; 71: 8-14.

44 Nguyen LP, Omoluabi O, Parra S, et al. Chronic exposure to beta-blockers attenuates inflammation and mucin content in a murine asthma model. Am J Respir Cell Mol Biol 2008; 38: 256-262.

45 Anderson WJ, Short PM, Williamson PA, et al. The inverse agonist propranolol confers no corticosteroid-sparing activity in mild-to-moderate persistent asthma. Clin Sci (Lond) 2014; 127: 635-643.

46 von Haehling S, Schefold JC, Jankowska E, et al. Leukocyte redistribution: effects of beta blockers in patients with chronic heart failure. PLoS One 2009; 4: e6411.

47 Dunzendorfer S, Wiedermann CJ. Modulation of neutrophil migration and superoxide anion release by metoprolol. J Mol Cell Cardiol 2000; 32: 915-924.

48 Garlichs CD, Zhang H, Mügge A, et al. Beta-blockers reduce the release and synthesis of endothelin-1 in human endothelial cells. Eur J Clin Invest 1999; 29: 12-16.

49 Roland M, Bhowmik A, Sapsford RJ, et al. Sputum and plasma endothelin-1 levels in exacerbations of chronic obstructive pulmonary disease. Thorax 2001; 56: 30-35.

50 McMurray JJ, Adamopoulos S, Anker SD, et al. ESC guidelines for the diagnosis and treatment of acute and chronic heart failure 2012: The Task Force for the Diagnosis and Treatment of Acute and Chronic Heart Failure 2012 of the European Society of Cardiology. Developed in collaboration with the Heart Failure Association (HFA) of the ESC. Eur J Heart Fail 2012; 14: 803-869.

51 Vestbo J, Hurd SS, Agusti AG, et al. Global strategy for the diagnosis, management, and prevention of chronic obstructive pulmonary disease: GOLD executive summary. Am J Respir Crit Care Med 2013; 187: 347-365.

52 Quint JK, Herrett E, Bhaskaran K, et al. Effect of $\beta$ blockers on mortality after myocardial infarction in adults with COPD: population based cohort study of UK electronic healthcare records. BMJ 2013; 347: f6650.

53 Egred M, Shaw S, Mohammad B, et al. Under-use of beta-blockers in patients with ischaemic heart disease and concomitant chronic obstructive pulmonary disease. QJM 2005; 98: 493-497.

54 Chen J, Radford MJ, Wang Y, et al. Effectiveness of beta-blocker therapy after acute myocardial infarction in elderly patients with chronic obstructive pulmonary disease or asthma. J Am Coll Cardiol 2001; 37: 1950-1956.

55 Lipworth BJ, Williamson PA. Think the impossible: beta-blockers for treating asthma. Clin Sci (Lond) 2010; 118: $115-120$ 
63 Lainscak M, Podbregar M, Kovacic D, et al. Differences between bisoprolol and carvedilol in patients with chronic heart failure and chronic obstructive pulmonary disease: a randomized trial. Respir Med 2011; 105: Suppl. 1, S44-S49.

64 van der Woude HJ, Zaagsma J, Postma DS, et al. Detrimental effects of beta-blockers in COPD: a concern for nonselective beta-blockers. Chest 2005; 127: 818-824.

65 Bundkirchen A, Brixius K, Bölck B, et al. Beta 1-adrenoceptor selectivity of nebivolol and bisoprolol. A comparison of [3H]CGP 12.177 and [125I]iodocyanopindolol binding studies. Eur J Pharmacol 2003; 460: 19-26.

66 Kamp O, Metra M, Bugatti S, et al. Nebivolol: haemodynamic effects and clinical significance of combined beta-blockade and nitric oxide release. Drugs 2010; 70: 41-56.

67 Nuttall SL, Routledge HC, Kendall MJ. A comparison of the beta1-selectivity of three beta1-selective beta-blockers. J Clin Pharm Ther 2003; 28: 179-186.

68 Wheeldon NM, McDevitt DG, Lipworth BJ. Selectivity of antagonist and partial agonist activity of celiprolol in normal subjects. Br J Clin Pharmacol 1992; 34: 337-343.

69 Mentz RJ, Wojdyla D, Fiuzat M, et al. Association of beta-blocker use and selectivity with outcomes in patients with heart failure and chronic obstructive pulmonary disease (from OPTIMIZE-HF). Am J Cardiol 2013; 111 : 582-587.

70 DiNicolantonio JJ, Fares H, Niazi AK, et al. $\beta$-Blockers in hypertension, diabetes, heart failure and acute myocardial infarction: a review of the literature. Open Heart 2015; 2: e000230.

71 Short PM, Anderson WJ, Williamson PA, et al. Effects of intravenous and oral $\beta$-blockade in persistent asthmatics controlled on inhaled corticosteroids. Heart 2014; 100: 219-223.

72 Lipworth BJ, Irvine NA, McDevitt DG. A dose-ranging study to evaluate the beta 1-adrenoceptor selectivity of bisoprolol. Eur J Clin Pharmacol 1991; 40: 135-139.

73 Anderson WJ, Short PM, Manoharan A, et al. Influence of $\beta 2$-adrenoceptor 16 genotype on propranolol-induced bronchoconstriction in patients with persistent asthma. Ann Allergy Asthma Immunol 2014; 112: 475-476.

74 Lanfear DE, Jones PG, Marsh S, et al. Beta2-adrenergic receptor genotype and survival among patients receiving beta-blocker therapy after an acute coronary syndrome. JAMA 2005; 294: 1526-1533.

75 Sehnert AJ, Daniels SE, Elashoff M, et al. Lack of association between adrenergic receptor genotypes and survival in heart failure patients treated with carvedilol or metoprolol. J Am Coll Cardiol 2008; 52: 644-651.

76 Pitt B, Reichek N, Willenbrock R, et al. Effects of eplerenone, enalapril, and eplerenone/enalapril in patients with essential hypertension and left ventricular hypertrophy: the 4E-left ventricular hypertrophy study. Circulation 2003; 108: 1831-1838.

77 McMurray JJ, Packer M, Desai AS, et al. Angiotensin-neprilysin inhibition versus enalapril in heart failure. $N$ Engl J Med 2014; 371: 993-1004.

78 Cargill RI, Lipworth BJ. Acute effects of ANP and BNP on hypoxic pulmonary vasoconstriction in humans. Br J Clin Pharmacol 1995; 40: 585-590.

79 Cargill RI, Lipworth BJ. Atrial natriuretic peptide and brain natriuretic peptide in cor pulmonale. Hemodynamic and endocrine effects. Chest 1996; 110: 1220-1225. 